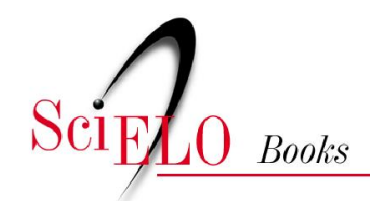

\title{
Refletindo acerca das organizações da sociedade civil e o atendimento às pessoas com deficiência em Campina Grande (PB)
}

\author{
Cleônia Mendes de Sousa
}

\section{SciELO Books / SciELO Livros / SciELO Libros}

SOUZA, CM. Refletindo acerca das organizações da sociedade civil e o atendimento às pessoas com deficiência em Campina Grande (PB). In DAVI, J., MARTINIANO, C., and PATRIOTA, LM., orgs. Seguridade social e saúde: tendências e desafios [online]. 2nd ed. Campina Grande: EDUEPB, 2011. pp. 219-235. ISBN 978-85-7879-193-3. Available from SciELO Books <http://books.scielo.org>.

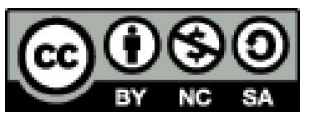

All the contents of this work, except where otherwise noted, is licensed under a Creative Commons Attribution-Non Commercial-ShareAlike 3.0 Unported.

Todo o conteúdo deste trabalho, exceto quando houver ressalva, é publicado sob a licença Creative Commons Atribuição Uso Não Comercial - Partilha nos Mesmos Termos 3.0 Não adaptada.

Todo el contenido de esta obra, excepto donde se indique lo contrario, está bajo licencia de la licencia Creative Commons Reconocimento-NoComercial-CompartirIgual 3.0 Unported. 


\section{Refletindo acerca das organizações da sociedade civil e o atendimento às pessoas com deficiência em Campina Grande (PB)}

Cleônia Mendes de Sousa

\section{Introdução}

O presente artigo é fruto de uma pesquisa realizada através do Programa Institucional de Iniciação Científica (PROINCI/UEPB) que teve por objetivo caracterizar as Organizações da Sociedade Civil de atendimento as pessoas com deficiência, na cidade de Campina Grande (PB). A referida pesquisa foi do tipo documental, com abordagem quanti-qualitativa. $\mathrm{O}$ universo pesquisado se constituiu das seis Organizações cadastradas no Conselho Municipal de Assistência Social. Os dados foram coletados nos documentos (atas, estatutos, pareceres etc.) existentes no citado Conselho. De maneira geral, os resultados evidenciaram que as organizações pesquisadas realizam um trabalho relevante. Porém, não conseguem atender toda a demanda reprimida. O que demonstra a necessidade de ser cobrado dos órgãos governamentais a responsabilidade com as políticas públicas nesta área. 
A Organização Mundial de Saúde (OMS) aponta a existência de $10 \%$ da população mundial com algum tipo de deficiência, sendo que a área mental representa 5\% deste total (ROY, 2000).

Esses dados ratificam que este segmento da população é significante tanto quantitativamente, como também, para a construção de uma sociedade mais democrática e com justiça social; faz-se necessário o respeito à diversidade humana nos diversos aspectos (cultural, gênero, raça, pessoas com deficiência etc.).

Assim sendo, esse segmento da população deve ter uma atenção específica por parte do poder público estatal, seja no âmbito federal, estadual ou municipal, através de políticas sociais e legislação direcionada a esta área, cabendo à sociedade civil organizada participar como parceira em todos os níveis, só desta maneira essas pessoas poderão ter de fato os seus direitos efetivados.

No Brasil as políticas sociais direcionadas a pessoa portadora de deficiência surgem nos anos noventa, a partir da Constituição de 1998, sendo responsabilidade do Estado. Todavia, o que ainda se constata é que a maioria das instituições que atuam nesta área está inserida na denominada esfera privada filantrópica, porém pública (ROY, 2000, p: 217).

Com a Constituição Federal de 1988, a Assistência Social passa a integrar a Seguridade Social, juntamente com a Saúde e a Previdência Social, sendo considerada uma política social, "direito do cidadão e dever do Estado", deixando de ser concebida como favor, caridade para ser tida como direito social.

Apesar desses avanços significativos no plano jurídico, principalmente quando a carta magna reconhece as representações da sociedade como interlocutor legítimo na sua capacidade de reivindicar direitos, paradoxalmente, a partir da década de noventa, tem se constatado uma "limitação - restrição" no que se refere à 
intervenção estatal em termos de programas e ações na área social. Isto em decorrência da adesão do país ao projeto neoliberal, o qual prevê um "Estado mínimo", contrapondo-se ao chamado "Estado de bem-estar social", no qual o Estado era o grande responsável pela execução das políticas e programas assistenciais.

No caso específico de Campina Grande, também observamos que existe um maior número de Organizações da esfera privada (sociedade civil), porém, de caráter público, que prestam atendimento às pessoas com deficiência.

Este estudo é resultado de uma pesquisa que foi contemplada pelo Programa Institucional de Iniciação Científica - PROINCI/ UEPB (cota 2006/2007) e teve como principal objetivo: caracterizar as Organizações da Sociedade Civil de atendimento às pessoas com deficiência na cidade de Campina Grande - PB.

A pesquisa foi documental, de natureza qualitativa, desenvolvida através de material bibliográfico. A coleta dos dados foi feita nas fichas de cadastros, pareceres e documentos das Organizações pesquisadas, existentes no Conselho Municipal de Assistência Social, por ser o órgão que tem envolvimento direto com a temática estudada.

Com relação à pesquisa documental, Ferrari (1982, p. 224) assim se expressa:

A pesquisa bibliográfica não deve ser confundida com a documental, pois a primeira pressupõe um levantamento mais amplo, enquanto a segunda são fontes acabadas que não receberam ainda um tratamento analítico ou se isso aconteceu ainda podem receber uma nova reformulação de acordo com os objetivos da pesquisa.

Os dados qualitativos foram submetidos à análise de conteúdo e os quantitativos foram submetidos a tratamento estatístico. 
O universo pesquisado constou de seis (06) Organizações da Sociedade Civil de Atendimento à pessoa com deficiência, na cidade de Campina Grande, e que estavam cadastradas no Conselho Municipal de Assistência Social.

Este estudo torna-se relevante à medida que propõe construir um conhecimento relacionado às pessoas com deficiência, fornecendo aos profissionais e alunos envolvidos com a temática, subsídios que possam nortear a reflexão e intervenção na realidade estudada, uma vez que algumas dessas Organizações constituem campo de estágio de serviço social.

\section{As práticas sociais direcionadas às pessoas com deficiência}

De maneira geral, a sociedade, inicialmente, adotou o paradigma denominado de "exclusão social", no qual essas pessoas, por serem consideradas incapazes e inválidas, eram excluídas de todos os níveis da vida em sociedade, não tendo nenhum tipo de atendimento, como se não fizessem parte da sociedade. Conforme Sassaki (1997, p. 31), “se algumas culturas simplesmente eliminava as pessoas deficientes, outras adotaram a prática de interná-las em grandes instituições de caridade, junto com doentes e idosos".

Posteriormente, foi adotado o paradigma da institucionalização ou atendimento segregado, que prevaleceu por vários séculos. A deficiência era tida como uma doença e, portanto, a pessoa era internada em instituições, não tendo um atendimento educativo, apenas médico e ou terapêutico. Neste período houve a criação das grandes instituições direcionadas por áreas de deficiência.

A partir das limitações dessa prática social da segregação, surgidas ao longo do tempo, começou a despontar um movimento de crítica à institucionalização, sendo criados alguns serviços com 
a perspectiva da integração social da pessoa com deficiência, cujo objetivo principal era capacitar, habilitar e reabilitar essas pessoas para "integrar a sociedade" nos sistemas sociais gerais, tais como: educação, trabalho, lazer e família, surgindo assim, as denominadas "classes especiais" e "escolas especializadas" nas diversas áreas de deficiência (mental, visual, de áudio-comunicação etc.).

No caso específico do Brasil, foi no início da década sessenta (século XX) que foi inserida na Política Nacional da Educação a questão da "educação de deficientes" ou da "educação especial", dando origem, assim, às denominadas "classes especiais", as quais atendiam alunos com deficiências de tipos diferentes em uma única sala e funcionava no mesmo espaço físico das escolas públicas de ensino regular.

Uma das críticas feita a este paradigma por Sassaki (1997) refere-se ao fato de que a integração social constitui um espaço unilateral da pessoa com deficiência que tem de se esforçar ao máximo para mostrar que é capaz de utilizar os espaços físicos e sociais para poder estudar, trabalhar, ter lazer etc.

$\mathrm{Na}$ década de noventa desponta um novo paradigma, o da "inclusão social", tendo como marco a legislação internacional, a exemplo da Declaração de Salamanca. A referida declaração é o resultado das deliberações da Conferência Mundial de Educação Especial, realizada na cidade de Salamanca (Espanha de 07 a10 de junho de 1994) e contou com a participação de 88 países, inclusive o Brasil, e 25 Organizações internacionais.

A Declaração de Salamanca define princípios, políticas e práticas a serem seguidas pelos países signatários com relação à educação de pessoas com deficiência.

O campo educacional saiu na frente para conscientizar o mundo a respeito do paradigma da inclusão, segundo o qual todas as pessoas, com ou sem condições atípicas, devem estudar 
juntas, exigindo para isto uma mudança radical em todas as partes componentes do processo ensino-aprendizagem (ABRANCHES, 2000, p.103-104).

A inclusão de pessoas com deficiência na rede regular de ensino é um tema polêmico e complexo. O mesmo atualmente está em evidência na mídia e vem sendo debatido por vários estudiosos da área além de estar garantida na legislação vigente. A inclusão social é definida como sendo:

Um processo no qual a sociedade se adapta para poder incluir, em seus sistemas sociais gerais, pessoas com necessidades especiais e, simultaneamente, estas se preparam para assumir os seus papéis na sociedade. (SASSAKI, 1997, p. 14)

A Constituição Federal (1988), no seu artigo 208, inciso 1ll, coloca que o dever do Estado com a educação será efetivado mediante a garantia de: "atendimento educacional especializado aos portadores de deficiência, preferencialmente na rede regular de ensino" (BRASIL, 2001). Desta forma, a denominada "educação especial" hoje não pode ser dissociada da Política Nacional de Educação e, conseqüentemente, integra o ensino regular.

A Lei de Diretrizes e Bases da Educação (LDB, No 9.394 de 20 de Dezembro de 1996) ratifica o preceito constitucional quando determina: "entende por educação especial, para efeitos dessa lei, a modalidade de educação, oferecida preferencialmente na rede regular de ensino, para educandos portadores de necessidades especiais" e dá outras providências, nos incisos 1, 11 e 111 (BRASIL, 1996).

A legislação em vigor está embasada no paradigma da inclusão. Ou seja, propõe a "educação inclusiva" quando se refere especificamente a educação. Porém, a inclusão nas escolas não pode se limitar à legislação. Ela envolve vários aspectos, dentre eles, mudanças de 
mentalidades e compromisso político. É necessário ainda, que as escolas e os profissionais envolvidos criem condições reais para que as escolas sejam inclusivas e que os alunos sejam acolhidos com suas diferenças e estimulados a superarem as limitações.

A Política Nacional para a Integração da Pessoa Portadora de Deficiência (Lei No 7.853 de 24 de Outubro de 1989) foi regulamentada pelo decreto 3.298 de 20 de Dezembro de 1999 e tem os seguintes objetivos:

I - o acesso, ingresso e a permanência da pessoa portadora de deficiência em todos os serviços oferecidos à comunidade;

II - integração das ações dos órgãos e das entidades públicas e privadas nas áreas de saúde, educação, trabalho, transporte, assistência social, edificação pública, previdência social, habitação, cultura, desporto e lazer, visando à prevenção das deficiências, à eliminação de suas múltiplas causas e à inclusão social;

III - desenvolvimento de programas setoriais destinados ao atendimento das necessidades especiais da pessoa portadora de deficiência;

IV - formação de recursos humanos para o atendimento da pessoa portadora de deficiência; e

V - garantia da efetividade dos programas de prevenção, de atendimento especializado e de inclusão social. (BRASIL, 1999)

No ano de 2008 foi publicada a Política Nacional de Educação Especial, na Perspectiva da Educação Inclusiva, que define caminhos para educação especial dentro dos parâmetros da educação inclusiva. 
Apesar dos avanços conquistados por este segmento de pessoas com deficiência, principalmente no que refere à legislação, a realidade evidencia dificuldades no que se refere à efetivação dos direitos formais. O que exige cada vez mais organização e controle social por parte dos diversos sujeitos sociais comprometidos com a questão.

A ampliação da esfera privada e redução do Estado têm ocasionado à transferência das responsabilidades estatais com a área social para a sociedade civil, especificamente no que se referem ao atendimento às pessoas com deficiência.

A Coordenadoria Nacional para Integração da Pessoa Portadora de Deficiência (CORDE) considera uma pessoa com deficiência:

Àquela que apresenta, em caráter permanente, perdas ou anormalidades de sua estrutura ou função psicológica, fisiológica ou anatômica, que geram dificuldades para o desempenho de atividades, dentro do padrão normal para o ser humano (ROY, 2000, p.21).

$\mathrm{Na}$ literatura e legislação específica não encontramos uma terminologia única para se referir a este grupo social, sendo utilizados várias expressões, dentre elas: "pessoas com deficiência"; "pessoas portadoras de deficiência" e "portadores de deficiência". A maioria dos documentos oficiais utiliza "pessoa portadora de deficiência". No entanto, algumas organizações representativas questionam o termo "portador" por não condizer com a realidade.

Mais recentemente, a denominação "pessoas com necessidades especiais" foi adotada em alguns estudos e livros. Porém, Sassaki (1997) ao refletir sobre este assunto, afirma que este termo tem um significado mais amplo e engloba, além das diversas formas de deficiências (mental, fisica, visual e auditiva), as dificuldades de aprendizagem, distúrbios emocionais, transtornos 
mentais, problemas de conduta, distúrbios obsessivo compulsivo, dentre outros, motivo pelo qual ele não pode ser usado simplesmente como sinônimo de deficiência, já que engloba outras categorias.

Também é usada a expressão "necessidades educativas especiais" ao referir de maneira específica as necessidades na área educacional.

Em virtude desta polêmica e complexidade dos termos optamos em utilizar neste estudo a denominação pessoa com deficiência para especificar a pessoa que tem uma deficiência nas áreas: mental; fisica, visual e ou auditiva.

Nesta pesquisa denominamos Organizações da Sociedade Civil as diversas entidades filantrópicas e ou assistenciais; associações, institutos e demais organizações que atendem pessoas com deficiência que, embora estejam inseridas na esfera "privada", realizam um trabalho "público". Ou seja, apesar de consideradas públicas não são estatais.

Segundo Raichellis (2000 p. 29-30):

O privado é aqui representado por um conjunto heterogêneo de entidades que se distinguem das organizações puramente mercantis, ao exercer papel de intermediação na prestação de bens e serviços não contributivos, que não derivam da inserção do beneficiário no mercado de trabalho.

A ampliação dessa esfera privada evidencia a redução do Estado, onde ocorre a transferência das responsabilidades estatais com a área social para a sociedade civil. Ou seja, cada vez mais as Organizações assumem a execução das políticas sociais. 


\section{Apresentação dos resultados}

Os dados aqui apresentados são referentes as seis (06) organizações de atendimento as pessoas com deficiência cadastradas no Conselho Municipal de Assistência Social de Campina Grande/ $\mathrm{PB}$, no momento da coleta de dados. As Organizações pesquisadas foram: Associação de Pais e Amigos dos Excepcionais (APAE - ORG I); Centro Assistencial da Criança Excepcional (CACE -ORG II); Instituto Campinense de Assistência ao Excepcional (ICAE- ORG III); Instituto de Educação e Assistência aos Cegos do Nordeste (ORG IV); Associação dos Deficientes do Compartimento da Borborema (ASDCB-ORG V) e Sociedade Beneficente Lar de Maria (ORGVI).

Além das seis pesquisadas, tomamos conhecimento do funcionamento de mais duas, porém, não as incluímos no universo da pesquisa, pois não constavam informações das mesmas no citado Conselho, onde foi realizada a pesquisa documental.

Segundo relato dos documentos pesquisados, os motivos que justificaram a criação dessas Organizações foram: que a cidade de Campina Grande possuía uma demanda reprimida e a inexistência de serviços especializados por parte dos órgãos governamentais para atender as pessoas com deficiência.

A omissão dos poderes constituídos e a falta de recursos das famílias das pessoas com deficiência remetem muitas vezes ao abandono e à exclusão dessas pessoas.

Quanto à data de criação, a Organização mais antiga foi criada ainda na década de quarenta e somente uma foi fundada no ano de 2003. Ou seja, cinco delas foram criadas no período que antecede a ofensiva neoliberal (década de 90). Isto confirma que o atendimento a este grupo de população, ao longo dos tempos, tem sido no geral, assumido pelas Organizações da Sociedade Civil, inserida na denominada esfera privada. 
Todavia, a partir da década de noventa, se configura cada vez mais a desresponsabilidade do Estado na área social. Para tanto, o mesmo exalta a "solidariedade" e a "filantropia" e se coloca como parceiro da sociedade. $O$ que constatamos é uma tendência ao que Iamamoto (1998, p: 43) denomina de refilantropização Social: "em que grandes corporações econômicas passam a se preocupar e intervir na questão social dentro de uma perspectiva da filantropia empresarial".

As Organizações pesquisadas prestam vários serviços, tais como: atendimento à família; atendimento médico; psicológico; fonoaudiológico; fisioterápico; de enfermagem; orientação pedagógica; orientação na área de serviço social; grupos de recreação e atividades culturais. $\mathrm{O}$ acesso aos serviços se dá de forma espontânea e através de encaminhamentos de profissionais especializados.

Constatamos que o público alvo das Organizações pesquisadas é bem diversificado, sobretudo no que diz respeito à faixa etária atendida. 33,3\% das Organizações atendem crianças, adolescentes e adultos, outras $33,3 \%$ atendem crianças e adolescentes, seguidos de $16,7 \%$ que tem como usuários todas as faixas etárias (crianças, adolescentes e adultos) e, por fim, 16,7\% atendem somente adultos. Vale ressaltar que a demanda por serviços não corresponde ao número de atendimento prestado, havendo um processo de seletividade e, conseqüentemente, de exclusão do atendimento.

Esta realidade é resultante da reforma do Estado, ocorrida no Brasil na década de noventa e que está em consonância com os ditames do projeto neoliberal, o qual propõe políticas sociais seletivas e residuais.

No tocante às áreas das deficiências que as organizações atuam, cinco delas atendem as pessoas com deficiência mental, ou seja, este tipo de deficiência é a mais atendida. 
É bom deixar claro que existem níveis diferenciados de deficiência mental, os quais devem ser considerados apenas no sentido de serem trabalhadas as limitações de maneira mais adequadas, visando superá-las, tanto pelos familiares, profissionais e a sociedade de maneira geral. Pois nem sempre a pessoa com deficiência é dependente ou totalmente incapaz. Porém, é necessário que a sociedade civil organizada e os órgãos públicos estatais (nas várias esferas), criem condições favoráveis para receber a pessoa com deficiência nos diversos equipamentos sociais, pois só assim, será colocada em prática a "inclusão social".

Segundo estimativas da Organização Mundial de Saúde (apud CNBB, 2006), existem aproximadamente 24,6 milhões de pessoas com deficiência no Brasil, sendo que as maiores porcentagens estão nas regiões Norte $(16,1 \%)$ e Nordeste $(17,7 \%)$. O Estado com maior proporção é a Paraíba com 18,8\% (CENSO 2000, apud CNBB, 2006).

Esses dados vêm constatar que a maior incidência de pessoas com deficiência localiza-se nas classes sociais de baixa renda da população. Conforme Ribas (1983), isto se deve principalmente ao fato dessa população estar sujeita à carência de alimentação, falta de saneamento básico e precários serviços de saúde, dentre outros.

No que se refere ao número de pessoas atendidas pelas Organizações, os documentos pesquisados apontam que em três organizações (ORG I, ORG II e ORG III) existe uma lista de espera para o atendimento, enfatizando assim a necessidade de ampliação de vagas. Confirmando a necessidade do poder público assumir a responsabilidade com a política para as pessoas com deficiência, no município de Campina Grande.

As Organizações pesquisadas, em sua maioria, funcionam em horário integral e possui um horário de atendimento definido e sistemático, a única exceção é a Associação dos Deficientes do Compartimento da Borborema (ASDECB) que funciona de 
acordo com a demanda, com realização de atividades que podem variar na quantidade e periodicidade, já que ela se caracteriza mais como uma organização de mobilização e defesa dos direitos dos seus associados.

Conforme as fontes pesquisadas, os objetivos das organizações são os seguintes:

a) "Habilitação e reabilitação de pessoas com seqüelas neuromusculares e de pessoas com deficiências mentais" (ORG I).

b) "Tem como objetivo o tratamento e habilitação para pessoas com deficiência, seqüelas neuromusculares e reabilitação para portadoras de deficiência mental e transtorno comportamental" (ORG II).

c) "Proporcionar ao cliente a vencer suas dificuldades e conscientizar a família de modo a cooperar na reabilitação. $\mathrm{O}$ usuário é preparado para conhecer seus direitos, através da descoberta de suas potencialidades integra-se a comunidade, podendo assim realizar-se como indivíduo útil dentro do contexto social ao qual pertence" (ORG III).

d) "Contribuir com o processo de educação, reabilitação, assistência e inclusão social das pessoas com deficiência. Divulgar trabalhos desenvolvidos com o intuito de expandilos por diversas localidades da Paraíba. Sensibilizar escolas, associações e comunidade em geral acerca de direitos e potencialidades. Promover intercâmbios do Instituto com outras instituições e/ou associações afins” (ORG IV).

e) "Promover cursos profissionalizantes, favorecer um espaço de conscientização e reivindicações para garantir os serviços e políticas públicas de atendimento às pessoas com deficiência. Proporcionar melhores condições de vida às 
pessoas com deficiência para desenvolvimento de suas potencialidades. Promover campanhas beneficentes em prol dos deficientes. Estimular, orientar e desenvolver atividades, reabilitar e capacitar nos planos físicos, psicológicos, social, e profissional. Defender os direitos e os interesses coletivos e individuais dos seus associados" (ORGV).

f) "Amparar excepcionais carentes e abandonados de ambos os sexos" (ORGVI).

Como podemos identificar as Organizações possuem objetivos diversos, sendo a reabilitação dos usuários mencionada por cinco delas.

As ORGs I, II e III possuem uma equipe multiprofissional constituída de médicos, psicólogos e assistentes sociais; a equipe técnica da ORG IV é composta de assistente social e psicóloga; a ORGV não tem equipe técnica, enquanto a ORGVI possui apenas o profissional de serviço social. No atendimento à pessoa com deficiência se faz necessário a existência de uma equipe interdisciplinar especializada na área.

\section{Considerações finais}

A reflexão acerca das Organizações da Sociedade Civil e o atendimento às pessoas com deficiência no município de Campina Grande nos remete, obrigatoriamente, à compreensão da estrutura da sociedade, bem como a análise da política direcionada a este segmento da população.

Concordamos que nas últimas décadas houve um avanço significativo na legislação referente às pessoas com deficiência e que o paradigma da "inclusão social" é o que tem uma proposta mais avançada no que se refere ao atendimento a essas pessoas 
(SASSAKI, 1997). Todavia, ainda existe uma distância entre a lei e a prática social para que elas possam ser consideradas sujeitos de direitos.

Através desse estudo, constatamos que as Organizações de Campina Grande realizam um trabalho relevante para seus usuários e suas famílias e que este é um tema pouco debatido na Academia e demais espaços da sociedade.

Estas Organizações têm buscado inserir as pessoas com deficiência na sociedade, seja pela inserção no mercado de trabalho ou em ações que coincidem com o calendário das datas comemorativas da cidade de Campina Grande - PB.

No entanto, somos conscientes que o Estado (nas esferas federal, estadual e municipal) cada vez mais tem repassado para a sociedade civil a responsabilidade com a "questão social". Assim sendo, consideramos que um dos focos principais de atuação das Organizações é o de cobrar do Estado a assunção das políticas sociais e elas participarem na elaboração, gestão e controle social das políticas sociais, pois essas Organizações não podem reforçar a idéia errônea de que devem assumir o papel do Estado quando ele for omisso.

Acabar com o preconceito e aceitar a pessoa com deficiência é tarefa de todos. Não basta ficar nas "boas" intenções, é preciso agir de forma responsável para destruir os muros da diferença que separam os ditos "normais" daqueles que têm alguma deficiência. 


\section{Referências}

ABRANCHES, C. Inclusão no Trabalho. In: ABRANCHES, C. et al. Inclusão dá trabalho. Belo Horizonte: Armazém de Idéias, 2000.

BOLONHINI JÚNIOR, R. Portadores de necessidades especiais: as principais prerrogativas e a legislação brasileira. São Paulo: Arx, 2004.

BRASIL. Constituição da República Federativa do Brasil: texto constitucional de 05 de outubro de 1988. Brasília: Câmara dos Deputados, 2001.

BRASIL. Lei de diretrizes e bases da educação. № 9.394 de 20 de dezembro de 1996.

BRASIL. Ministério da Educação. Secretaria de Educação Especial. Política nacional de educação especial na perspectiva da educação inclusiva (Versão Preliminar). Brasília: MEC/SEESP, 2007.

BRASIL. Presidência da República. Subchefia para Assuntos jurídicos. Decreto $N^{\circ}$ 3.298. Dispõe sobre a Política Nacional para a Integração da Pessoa Portadora de Deficiência, consolida as normas de proteção, e dá outras providências. Diário Oficial da União, Brasília, DF, 20 dez. 1999.

CNBB. Conferência dos Bispos do Brasil. Fraternidade e pessoas com deficiência. Brasília: Cáritas Brasileira. 2006.

DAGNINO E. Sociedade civil e espaços públicos no Brasil. São Paulo: Paz e terra, 2002

DECLARAÇÃO DE SALAMANCA. Conferência Mundial de Educação Especial. Espanha, 1994.

FERRARI, T.A. Metodologia da pesquisa científica. São Paulo: McGraw-Hill, 1982. 
FREIRE, I. M. Um olhar sobre a diferença: interação, trabalho e cidadania. Campinas: Papirus, 2001.

IAMAMOTO, M.V. O serviço social na contemporaneidade: trabalho e formação profissional. São Paulo: Cortez, 1998.

MAZOTTA, M. J. S. Educação especial no Brasil: História e políticas públicas. 3.ed. São Paulo: Cortez, 1995.

MINAYO, C. S. (Org.). Pesquisa social: teoria método e criatividade. 4. ed. Petrópolis:Vozes, 1994.

RAICHELIS, R. Esfera pública e conselhos de assistência social: caminhos da construção democrática. 2. ed. São Paulo: Cortez, 2000.

INCLUSÃO: todos aprendem quando as crianças com deficiência vão à escola junto com as outras. Revista Nova Escola. São Paulo, n. 11, out. 2006. Edição Especial.

RIBAS, J. B. C. O que são pessoas deficientes. São Paulo: brasiliense, 1983.

ROY, L. Pessoas portadoras de deficiência. In: Capacitação em

Serviço social e política social: módulo 3: política social. Brasília: UNB, 2000.

SASSAKI, R. K. Inclusão: construindo uma sociedade para todos. 2. ed. Rio de Janeiro: LUVA, 1997.

SOUSA, C. M. M.; MOURA, D. B. Relatório final de pesquisa. Universidade Estadual da Paraíba -Programa Institucional de Iniciação Científica- PROINCI/2006/2007. 